\title{
Digital Futures: Exhibits at EVA London 2018
}

\author{
Irini Papadimitriou \\ V\&A, London \\ UK \\ i.papadimitriou@vam.ac.uk
}

\author{
Jonathan P. Bowen \\ Museophile, Oxford \\ UK \\ jonathan.bowen@lsbu.ac.uk
}

\begin{abstract}
As part of the EVA London 2018 conference on Electronic Visualisation and the Arts, V\&A Digital Futures has organised two special evening events, presenting a series of technology-based installations and enabling networking of those interested in digital art. Digital Futures has been focusing on topics around the impact of technology in art, society and contemporary culture, bringing to the fore questions of privacy and surveillance, big data, loT, technological obsolescence, identity and value in a digital age, to digital tools for civic engagement and action, and more. The platform enables critical discussions, but also long-term research projects and partnerships, using Digital Futures events for sharing, collaboration, and exchange, engage with global issues; sharing artistic processes, and demystifying technology.
\end{abstract}

Art and society. Contemporary culture. Digital art. Digital Futures. Technology. V\&A.

\section{INTRODUCTION}

Digital Futures (Papadimitriou 2018; Papadimitriou 2019) is a mobile and open platform aimed at displaying and discussing work by researchers, artists, designers, companies, and other professionals working with art, technology, design, science, and beyond.

The Digital Programmes team at the Victoria and Albert Museum (V\&A) in London was formed in 2008. Since 2010, the V\&A Digital Design Weekend (DDW) has been held annually at the $V \& A$ is aimed at emerging digital artists and designers (Papadimitriou, Prescott \& Rogers 2016; 2017).

The Digital Futures programme itself started at the $V \& A$ in 2012, to enable collaboration and exchange, but also to create a flexible space to share artistic processes, academic research, and engage with art, design, technology, and contemporary issues. Bringing together people from different backgrounds and disciplines has been a central and important part to the programme. Digital Futures is not fixed to a specific place; instead, it is a platform that changes continuously depending on participants, partners, themes, etc., exploring ideas from different perspectives.
As part of EVA London 2018, developing from Digital Futures events held in association with previous EVA London conferences - e.g., see Papadimitriou, Addis, et al. (2017) - we are holding for the first time two Digital Futures evening events. The first evening is to be held after the EVA London 2018 Symposium (Bowen et al. 2018) on the first day of the conference. The second evening is three days later, on the final day of the conference. Both evenings are at the BCS London office in Covent Garden, central London, also the venue for the EVA London 2018 conference itself.

\section{DEMONSTRATIONS AND EXHIBITS}

This year, for the first time, we used the EasyChair online submission system (http://easychair.org) and attracted 61 possible demonstrations and exhibits for Digital Futures; hence the decision to have two events to make it feasible to accept a good number of these. Some proved impractical at the BCS London office (on the first floor with relatively small life access), but around half of these were selected for inclusion.

The following demonstrations and exhibits are on display at the two EVA London 2018 Digital Futures events: 
1. Brendan Body. Animated Holographic Archaeopteryx.

2. Daniel Buzzo. Hybrid Drawing, Deep Maps, Augmented Realities.

3. Sean Clark. The Internet of Art Things aka ArtThings.

4. Laura Dekker. An Expressive Responsive Machine.

5. Eunice G. Duarte. This Is a Low Tech Movie.

6. Francesca Franco. Algorithmic Signs Five pioneers of computer art in conversation.

7. Philip Galanter. evoColorBox and evoColorWheel: Generative artworks that exercise the computational aesthetic evaluation of colour.

8. Oliver Gingrich, Evgenia Emets and Alain Renaud. Aura - A holographic brainwave interface.

9. Kyriaki Goni. eternal_u.inc.

10. Kyriaki Goni. The Aegean Datahaven: $A$ cooperative platform in the archipelago.

11. Hanna Haaslahti and Tyler Henry. Cosmetic Space.

12. Beverley Hood. Atopic Residency.

13. Tom Keene. Special Purpose Vehicle / Shadow Database.

14. Andy Lomas. Morphogenetic Creations: Vase forms.

15. Jon Malis. Transcolorations.

16. Anna Nazarova. Blue.

17. Sara Nevay and Christopher Lim. Textile Connections: The soft touch.

18. Paul O'Dowd. Robot Poetics: Materially sensitive drawing robot.

19. Joe Osmond. The Migrant's Lament.

20. Liviu Pop. Deep Transylvania (Un)covered.

21. Gareth Proskourine-Barnett. <Conc(re)te>.

22. Kristina Pulejkova. Modified.

23. Sabrina Recoules Quang. Between 0 and 1 "We are all there together" - The Dada data.

24. Elke Reinhuber, Benjamin Seide and Ross Williams. Secret Detours for Unspecified Screens.

25. Esther Rolinson and Sean Clark. Drawing Game.

26. Anouska Samms and Juhee Park. Content/Data/Object.

27. Paul Sermon. Touched.

28. Aphra Shemza. New Media Art, Technology, Innovation and the Future.

29. Carl Smith and Sarah Janes. Virtual Initiation.

30. Dario Srbic. (De)generative Art: Rulestransgressing algorithms.

31. David Upton. The Invisible Arp.

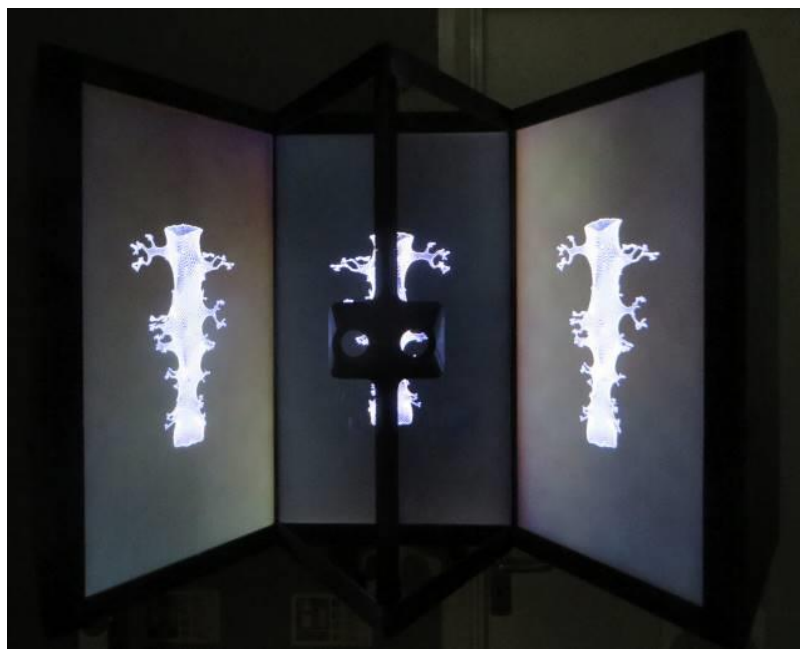

Figure 1: 'Constrained Forms' stereo installation at the EVA London 2017 Digital Futures exhibition

(Papadimitriou et al. 2017), by Andy Lomas, who is also exhibiting at the EVA London 2018 Digital Futures. (Photograph by Jonathan Bowen.)

\section{REFERENCES}

Bowen, J. P., Giannini, T., Polmeer, G., et al. (2018) States of being: Art and identity in digital space and time. In J. P. Bowen, J. Weinel, G. Diprose, \& N. Lambert (eds.), EVA London 2018: Electronic Visualisation and the Arts. BCS, Electronic Workshops in Computing. (This volume.)

Giannini, T. and Bowen, J. P. (eds.) (2019) Museums and Digital Culture: New perspectives and research. Springer, Series on Cultural Computing. (To appear.)

Papadimitriou, I. (2018) Digital Futures. Blog, V\&A, London, UK. http://www.vam.ac.uk/blog/tag/digitalfutures (accessed 10 May 2018).

Papadimitriou, I. (2019) Digital Futures and the 21st century museum. In Giannini \& Bowen (2019). (To appear.)

Papadimitriou, I., Addis, J., Lomas, A., Dekker, L., Singporewala, K., and Tresset, P. (2017) Digital Futures: Lumen Big Reveal. In J. P. Bowen, G. Diprose, \& N. Lambert (eds.), EVA London 2017: Electronic Visualisation and the Arts, pp. 438-440. BCS, Electronic Workshops in Computing. DOI: 10.14236/ewic/EVA2017.86

Papadimitriou, I., Prescott, A., and Rogers, J. (eds.) (2016) Engineering the Future as part of $V \& A$ Digital Design Weekend 2016. Uniform Communications.

Papadimitriou, I., Prescott, A., and Rogers, J. (eds.) (2017) Bridging Open Borders as part of V\&A Digital Design Weekend 2017. Uniform Communications. 